\title{
INCORPORAÇÃO DE AGENTES REPELENTES EM TÊXTEIS TÉCNICOS
}

\author{
V. KREUTZFELD ${ }^{1}$, R. B. VENTURELLI ${ }^{2}$, A. A. U. de SOUZA $^{2}$ e A. P. S. IMMICH ${ }^{1}$ \\ ${ }^{1}$ Universidade Federal de Santa Catarina, Engenharia Têxtil, Blumenau - SC \\ ${ }^{2}$ Universidade Federal de Santa Catarina, Departamento de Engenharia Química e \\ Engenharia de Alimentos, Florianópolis - SC \\ E-mail para contato: ana.immich@ufsc.br
}

\begin{abstract}
RESUMO - Estudos realizados pela Associação Brasileira da Indústria do PET comprovam que existe um déficit no índice de reciclagem do PET comparado a sua produção. Nos últimos anos, a quantidade deste polímero tem aumentado na composição de resíduos sólidos urbanos, sendo um polímero de difícil degradação. Uma alternativa à reciclagem do PET é o reprocessamento via eletrofiação. Esta técnica é versátil, de baixo custo e fácil reprodutibilidade. Assim, o que se pretende neste projeto de pesquisa é propor uma alternativa para reutilização do PET proveniente de garrafas descartáveis utilizando a técnica de eletrofiação para produção de um nãotecido. A este nãotecido foi incorporado óleo de citronela para agregar propriedades funcionais de repelência a insetos. Os resultados mostram que a eletrofiação produziu nãotecidos uniformes, com diâmetros de fibra regulares, sem a presença dos indesejados beads, indicando a viabilidade do processo de eletrofiação como alternativa a reciclagem de PET.
\end{abstract}

\section{INTRODUÇÃO}

Conforme a norma ABNT NBR 13370:2002 "Nãotecido é uma estrutura plana, flexível e porosa, constituída de véu ou manta de fibras ou filamentos, orientados direccionalmente ou ao acaso, consolidados por processo mecânico (fricção) e/ou químico (adesão) e/ou térmico (coesão) e combinações destes" mostrado por Maroni et al. (1999). O Nãotecido é um material que apresenta características semelhantes à de um tecido, que é um material produzido pelo entrelaçamento de um conjunto de fios de urdume e outro conjunto de fios de trama, formando o ângulo de (ou próximo a) $90^{\circ}$.

Existem diferentes formas de se obter um nãotecido, as técnicas mais utilizadas para fabricação consistem na formação de manta, uma estrutura ainda não consolidada, formada por uma ou mais camadas de véus de fibras ou filamentos obtidos por três processos distintos: via seca, via úmida e via fundida. Uma alternativa recente, de fácil aplicação e baixo custo para produção de nãotecido é a técnica de eletrofiação que combina duas técnicas chamadas electrospray (do inglês eletropulverização) e spinning (do inglês fiação). A eletrofiação é um processo que consiste na aplicação de uma alta voltagem em que uma solução polimérica contida em uma seringa ou capilar é carregada eletricamente e, sob influência de um campo elétrico, é fiada, estirada e coletada em uma superfície coletora para produzir fibras com um diâmetro relativamente pequeno, na ordem de nanômetros. 
Uma das principais características da nanofibra polimérica é a elevada área superficial, isso permite uma superfície de contato com o meio externo muitas vezes superior as das fibras convencionais (GOMES, 2014). O processo de eletrofiação para produção de artigos têxteis se tornou muito atrativo devido a sua metodologia de baixo custo, produzindo fibras a partir de uma grande variedade de materiais, de um modo relativamente simples, repetitivo e de fácil construção.

Os trabalhos de Li et al. (2004) mostraram que os parâmetros da solução a ser eletrofiada, tais como, viscosidade, condutividade elétrica e tensão superficial influenciam diretamente nas morfologias e na geometria das nanofibras. Estes parâmetros estão relacionados com as propriedades físico-químicas dos polímeros, dos solventes e com as interações do tipo polímero-solvente.

Uma vantagem da eletrofiação é a possibilidade de transformar o nãotecido em um artigo funcional, com características ativas como têxteis contendo fármacos para liberação controlada de medicamentos, peças de vestuário contendo microcápsulas de material hidratante que é liberado pelo atrito com a pele, toalhas de mesa com hidrorepelência, evitando manchas de líquidos coloridos, uniformes com propriedade antichama, oferecendo proteção em ambientes perigosos, entre outros. Estes nãotecidos funcionais são conhecidos como têxteis técnicos, que são estruturas especificamente projetadas e desenvolvidas para utilização em produtos, processos ou serviços de quase todas as áreas industriais e domésticas. São produtos que pretendem satisfazer requisitos funcionais bem determinados visando economia, segurança, praticidade e durabilidade definida conferindo propriedades a substratos têxteis de forma a proporcionar uma valorização estética, de conforto, proteção, limpeza e conservação.

A obtenção do nãotecido se dá a partir de uma variedade de polímeros sintéticos e/ou naturais, como os poliuretanos apresentado por Stankus et al. (2004), poli(vinilpirrolidona) estudado por McCann et al. (2005), poli(ácido lático) estudando por Yang et al. (2005), poli(álcool vinílico) apresentado por Costa et al. (2010), entre muitos outros. Uma alternativa de polímero para ser utilizado nessa técnica é o politereftalato de etileno (PET), objetivando oferecer mais uma alternativa de reciclagem deste polímero, que é largamente utilizado na indústria, sendo seu principal uso no segmento da indústria de embalagens. Estudos realizados pela Abipet (Associação Brasileira da Indústria do PET) comprovam que existe um déficit no índice de reciclagem do PET comparado a sua produção. Nos últimos anos, a quantidade deste polímero tem aumentado na composição de resíduos sólidos urbanos, sendo um polímero de difícil degradação, pois não existem bactérias na natureza capazes de degradar rapidamente o PET. Considerando que uma garrafa de PET leva cerca de 400 anos para se degradar no meio ambiente, existem inúmeras vantagens na sua reciclagem, diminuindo o volume de lixo nos aterros sanitários, economia de petróleo, economia de energia na produção de novos plásticos, geração de renda e empregos, entre outros.

Desta forma, este trabalho consiste em utilizar a técnica de eletrofiação para reprocessar o politereftalato de etileno, produzindo um tecido técnico funcional, no formato de uma cortina para proteção, e neste agregar um componente com propriedades de repelência a insetos, como por exemplo, o óleo essencial de citronela. $\mathrm{O}$ óleo de citronela é um repelente de insetos natural, possuindo propriedade antifúngica, seu uso é difundido e aprovado desde o ano de 1948. O órgão americano chamado United States Environmental Protection Agency o considera um tipo de biopesticida que não agride a saúde humana. 


\section{OBJETIVOS}

O que se pretende neste projeto de pesquisa é utilizar a técnica de eletrofiação para produção de cortinas de tecido nãotecidos eletrofiados com propriedades funcionais de repelência a insetos.

\section{MATERIAIS E MÉTODOS}

Os experimentos laboratoriais foram realizados no Laboratório de Transferência de Massa do Departamento de Engenharia Química e Engenharia de Alimentos da Universidade Federal de Santa Catarina.

\subsection{MATERIAIS}

Para a realização do trabalho foram utilizados o PET (Politereftalato de etileno) provenientes de garrafas $600 \mathrm{~mL}$ de coca-cola, diclorometano com 99,5\% de pureza, fabricado pela Synth, ácido trifluoroacético, com 99,8\% de pureza, fabricado pela Vetec, óleo de citronela, fabricado pela Distrol e álcool etílico absoluto P.A., com 99,5\% de pureza, fabricado pela Lafan Química fina LTDA.

\subsection{MÉTODOS}

Preparação da solução a ser eletrofiada: Para o preparo da solução a ser eletrofiada foi utilizado, como matéria-prima, garrafas descartáveis de PET (garrafa de $600 \mathrm{~mL}$ de cocacola). As garrafas foram cortadas em tiras e solubilizadas em uma solução contendo $20 \%$ ácido trifluoroacético e $80 \%$ de diclorometano com $10 \%$ PET $(\mathrm{m} / \mathrm{m})$. A solução foi mantida sob agitação magnética por 24 horas em temperatura ambiente, para completa dissolução do PET.

Preparo do óleo de citronela: Para o preparo da solução de citronela utilizou-se a proporção de $50 \%$ de óleo essencial da citronela diluído em $50 \%$ de álcool etílico obtendo-se uma mistura homogênea

Processo de produção do nãotecido: O nãotecido foi obtido por eletrofiação mediante as seguintes condições de trabalho: vazão do polímero e do óleo de citronela de $1,0 \mathrm{~mL} / \mathrm{h}$; voltagem aplicada as soluções de $25 \mathrm{kV}$; distância entre agulhas e coletor de $12 \mathrm{~cm}$; rotação da placa coletora de 5 RPM; volume infundido de 1,5 ml; umidade relativa de $68,4 \%$ e temperatura ambiente de $24,8^{\circ} \mathrm{C}$.

Incorporação do agente repelente: $\mathrm{O}$ agente repelente foi incorporado ao nãotecido por electrospraying, simultaneamente ao processo de electrospinning, sendo pulverizado aleatoriamente nas camadas do nãotecido sendo formado.

Análise de microscopia eletrônica de varredura (MEV): A análise morfológica dos nãotecidos produzidos foi realizada por microscopia eletrônica de varredura em um microscópio eletrônico da marca JEOL, modelo JSM-6390LV. 


\section{RESULTADOS}

Neste trabalho, o PET foi utilizado como matéria-prima para produção de um nãotecido eletrofiado para produção de cortinas de proteção com a funcionalidade de repelência a insetos. Os nãotecidos eletrofiados foram analisados por microscopia eletrônica de varredura e as imagens são mostradas a seguir.

Figura 1 - Nãotecido de PET eletrofiado com ampliação de 2000 vezes: a) sem adição de citronela; b) com citronela

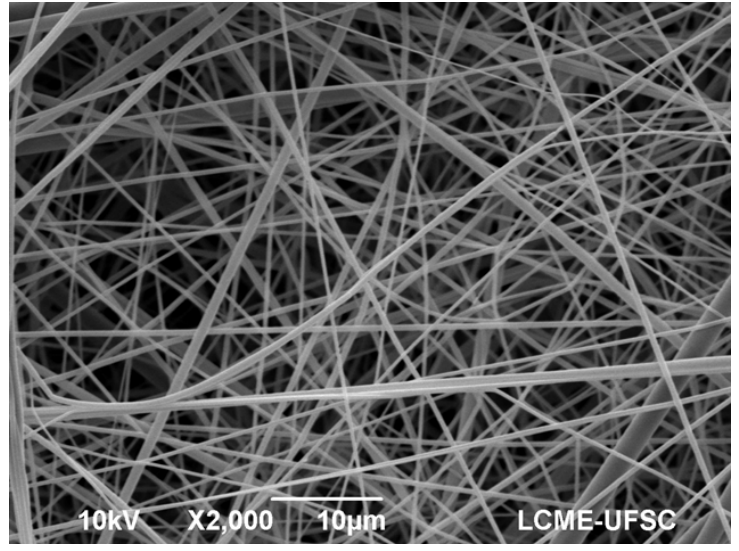

(a)

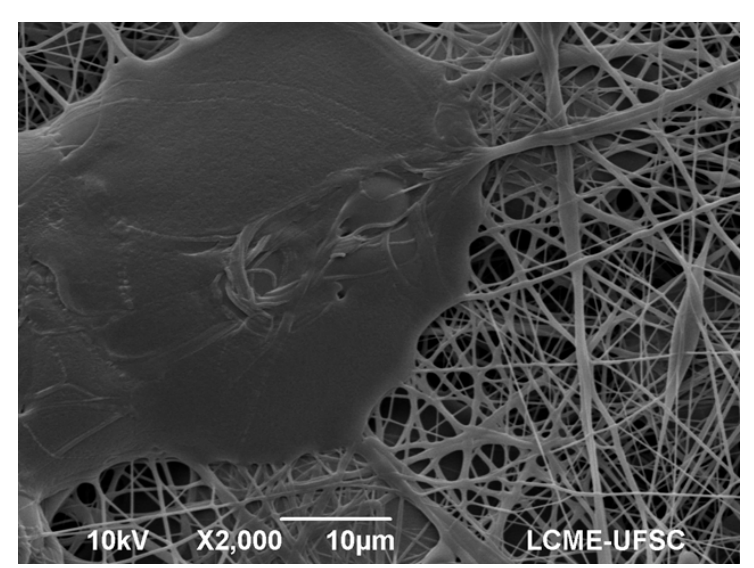

(b)

As análises de imagem mostram que o PET tem grande potencial de eletrofiação, produzindo fibras regulares, de diâmetro constante na escala submicrométrica, sem a presença dos indesejados beads, como mostra a Figura 1 (a). Beads são gotas de polímero não estiradas, que causam irregularidade no diâmetro das fibras e aparecem devido às condições de trabalho pouco controladas.

O processo de eletrofiação foi otimizado para produzir fibras íntegras, porém, com espaço tridimensional poroso para incorporação do agente repelente, como é evidenciado na Figura 1 (b), em que as gotas do repelente, que foram pulverizadas via electrospraying, encontram-se distribuídas entre as camadas de fibras.

\section{CONCLUSÃO}

Este estudo mostrou que a eletrofiação é uma técnica viável para a reciclagem do PET, permitindo a adição de compostos que aumentem o valor agregado do nãotecido, como por exemplo, a citronela. A eletrofiação produziu nãotecidos uniformes, com diâmetros de fibra regulares, sem a presença dos indesejados beads, indicando a viabilidade do processo de eletrofiação como alternativa a reciclagem de PET.

\section{REFERÊNCIAS}


MARONI, L. G.; WAGNER, T. P. F; SAITO, J.; LIMA, C. G. Classificação, Identificação e Aplicações de Nãotecidos. Abint, 1999. Disponível em http://www.abint.org.br/pdf/Manual_ntecidos.pdf. Acesso em: 26 de fev. 2015.

GOMES, P. H.; Implementação da técnica de eletrofiação de filmes poliméricos. Alfenas. pág. 2. (2014). Disponível em http://www.unifalmg.edu.br/fisica/files/file/TCCs/GomesPH.pdf. Acesso em: 26 de fev. 2015.

LI, D.; WANG, Y; XIA,Y. Electrospinning of nanofibers: reinventing the wheel. Adv Mater., v. 16, p. 1151-1170, 2004.

STANKUS, J.J.; GUAN, J.; WAGNER, W.R. Fabrication of biodegradable elastomeric scaffolds with sub-micron morphologies. J Biomed Mater Res. A v. 70(4), p. 603-14, 2004.

MCCANN, J. T.; LI, D.; XIA, Y. N. Electrospinning of nanofibers with core-sheath, hollow, or porous structures. J. Mater. Chem., v. 15, p. 735-738, 2005.

YANG, F.; MURUGAN, R.; WANG, S.; RAMAKRISHNA, S. Electrospinning of nano/micro scale poly(L-lactic acid) aligned fibers and their potential in neural tissue engineering. Biomaterials, v. 26, p. 2603-2610, 2005.

COSTA, R. G. F.; RIBEIRO, C.; MATTOSO, L. H. C. Morphological and Photocatalytic Properties of PVA/TiO ${ }_{2}$ Nanocomposite Fibers Produced by Electrospinning. J. Nanosci. Nanotechno., v. 10, p. 5144-5152, 2010.

CARDOSO, M. Óleos essenciais. Disponível em http://www.infoescola.com/quimica/oleosessenciais. Acesso em: 26 de fev. 2015.

ADAMI, A. Citronela. Disponível em http://www.infoescola.com/plantas/citronela. Acesso em: 26 de fev. 2015.

AKATU. Consumo consciente para um futuro sustentável. Disponível em http://www.akatu.org.br/Temas/Residuos/Posts/Sem-reciclar-todo-PET-nacional-Brasilimporta-o-res\%C3\%ADduo. Acesso em: 26 de fev. 2015. 